\title{
Parent-Child Interaction in Language Acquisition and Personality Development of Young Children in Monolingual and Bilingual Families
}

Sadullah Yılmaz

\author{
European University of Tirana(UET) Tirana/ Albania
}

yilmazsadullah@gmail.com

Mehmet Aslan

'Hëna e Plotë' Beder University

Tirana/ Albania

maslan@beder.edu.al

\begin{abstract}
Our differences throughout history led us to different methodologies in complying with educational rules as in our today's world there has been a great diversity of methodological approaches to education in different schools or institutions which stems from cultural, regional, political and personality differences. Together with globalization and development of technology the standards in education started to be based on materialistic issues in terms of facilities like labs, sports centers, smart boards, and even swimming pools. A parent in search of a school for hislher child is first to look above mentioned modern standards. Spiritual, moral values are started to be less important for parents and their children. As one of the two primary objectives, this article aims to bring these issues to the surface as they came to be obstacles in front of our children's developments as well as some educational issues, like truancy, lack of morality, parents' misguiding etc. As to gain a global perspective to the personality development of children, the role of parents together with teachers or instructors is also one of the important issues to be held in this article. As a second, more particular issue, approaches to the development of young children, parents' interactions and language development suggest some important elements of personality development in early childhood. Language is considered to be first step of a child's personality development as it shapes his lher character and temperament together with cognitive development. In this article as the second primary objective, it is aimed to get into depths of language development in monolingual and bilingual families and the children's acquisition of language in terms of speed, quality, comprehension, adaptation, and ability of learning two or more languages at the same time.
\end{abstract}

Keywords: Personality development, language acquisition, monolingual and bilingual families.

\section{INTRODUCTION}

As the study is mainly based on development of children in terms of language and personality; teacher's role is essential in all parts of child's life. Nonetheless, parents are also teachers who are to be considered volunteers and pioneers of education. Teachers have an undeniable role in inculcating moral values among students. Students' moral values are taken from various sources; family, friends, work place, observed events, reading, thinking and experiences introduce many moral values that keep us at different operative and intentional levels. We should conceptualize education as a whole, having to do directly with all approaches and methodologies. Teacher's role either in class or off the class cannot merely be restrained to an instructor who teaches what is in the curriculum; teachers also have many other roles as sometimes they are second parents to students, some other times, therapists, psychologists, and more importantly role models for students. It is one of teacher's duties towards education to try to make students achieve the best they can, and when that requires teaching them the moral values of the society they live in, then that's what a good teacher should do as part of student's personality development and language acquisition to a wider extent. 
The most essential factor in language development, however, is parental guidance through which a child may acquire two or more languages and have more developed cognitive skills. Children need to have the opportunity to solve problems and discover the world around them. On the other hand, after age five learning capacity of children is not the same as early infant ages; their inborn, internal ability gradually declines, and after age five the biggest opportunity of learning more than one language is not of that much advantageous. There is strong evidence that children may never acquire a language if they have not been exposed to a language before they reach the age of 6 or 7 . Children between the ages of 2 and 6 acquire language so rapidly that by 6 they are competent language users (Clark, 2000). There is, however, much more variation in how well and how quickly individuals acquire a second language. Nevertheless, scanted studies on the issue don't provide concrete evidence that there are biological restrictions for second language learning or that children have discovered advantages over adults. "It is in children's use of exploratory language - the language of wondering, their inquiring, their conjecturing, their considering, their imagining - that we are occasionally able to glimpse through windows into our children's thought." (Lindfors, 1991, pp. 8, 9).

This study together with scanted literature suggests that the more words babies hear, the faster they learn to talk. One of the surprising hypotheses suggested in this study is that bilingual family settings for learners are flexible and may acquire two languages in the time in which monolinguals acquire one. As related to personality development, teachers would find it easier to teach moral values and have bilingual students adapt the societal expectations in this regard. It is also observed that educational problems such as truancy, drug usage, drop outs etc. are less seen among bilingual students in relation to their healthy parent-child interactions since infancy. However, this study as a first step to further empirical studies is mainly based on literature review and observations.

\section{LANGUAGE DEVELOPMENT}

Language development is also a biological process through which stems some other cognitive and corporal skills. We human beings, unlike animals, learn everything from the beginning which made psychologists and scientists focus on learning skills. There are some steps that every child takes to gain language development. These steps as commonly accepted are as follow:

- Physical and Motor Development (walking, hand movement)

- Cognitive Development (imitation, memory, categorization)

- Emotional Development (Positive Emotions, Negative Emotions

- Social and Language Development

- Family and Society

Language is inextricably entwined with our mental life. Our perceiving, our remembering, our attending, our comprehending, our thinking.in short, all of our attempts to make sense of our experience in the world... (Lindfors, 1991, p. 8)

All languages - no matter where or how they are used (spoken, signed, or written) - share important properties that distinguish them from other kinds of communication systems. Young children and babies are able to recognize differences between sound patterns of any language. Infants hear their mother's voices before birth and know the rhythm of their mother language as newborns. When the baby is born, helshe is equipped with ability of discriminating the sounds of all languages. Although there are many differences in parent-child interaction patterns around the world, virtually all normally developing children become language users at the same rate (Clark, 2000). Blocks of language or sound patterns are known as phonemes which different studies show as babies being more familiar with than adults. A child's language constantly develops and changes. Adults are not as active as children in language communication as it is one of the basic needs for babies to be heard and to hear. 


\subsection{Parents Interactions in Language Development}

In the average child, at whatever developmental stage we observe, language is alive and well. Children's language development is a creative process that only needs a rich environment to thrive (Lindfors, 1991). The rich environment is mostly provided by parents who are also part of the environment that helps child's language acquisition.

"The essential features of the environment that influence children's development are their relationships with the important people in their lives..." as people interacting with them are considered to be more important compared to the educational settings; "... Beginning with their parents and other family members, and extending outward to include child care providers, teachers, and coaches - within the places to which they are exposed - from playgrounds to libraries to schools to soccer leagues." (National Scientific Council on the Developing Child, 2004, p. 4).

An important thing to be noted here is that child's understanding of the language develops through parents instructional interactions which helps child to speak later on. Understanding the language happens faster than and before the ability of speaking. For example, if a mother tells her infant child to put the toys back in the toy chest, he may follow her instructions even though he can't say what she said. A collaboration of caregiving by father and mother helps in development of the language, while guiding, responding the needs of the child and playing they create a kind of bond that help attachment and language development. Vygotsky (1986) put forward as a basis of argument that social interactions with adults within the cultural settings of society are of central importance to cognitive development. Building on Vygotsky's theories, Rogoff (1990) put forward the idea that skill development involves the interaction of two parties, a teacher (an adult) and a learner (a child). She called this an "apprenticeship-type relationship" that required "guided participation" happening during daily experiences. As mother is the main caregiver she is considered as the most essential asset with her role of language development. The process of language development is also with modifications of the learned and self-correction in which parents' role is vital to gain needed skills, accommodation and adaptation of new settings and situations. The process is also full of modifications as speaking itself requires changes in verbal symbols as a languages are mobile not stable.

\subsection{Language Development in Monolingual and Bilingual Families}

There are a number of practice skills identified and used in training staff as Gilkerson \& Taylor numbered them;

These skills in relationship-based early intervention included the capacity to: 1) listen carefully; 2) demonstrate concern and empathy; 3) promote reflection; 4) observe and highlight the parent/child relationship; 5) respect role boundaries; 6) respond thoughtfully in emotionally intense interactions; and 7) understand, regulate, and use one's own feelings (Gilkerson \& Taylor Ritzler, in press). These skills apply to relationships on a number of different levels, both with bilingual and monolingual families. The speed of the language development doesn't depend on teaching one or two languages at the same time, it mostly rely on parents' effective interaction with their kid(s);

"How often and how well parents communicate with their children is a strong predictor of how rapidly children expand their language learning." Suggesting that language acquisition is not merely based on parental care of infants' biological needs but also "Encouraging children to express their needs, ideas, and feelings whether in one language or two enriches children linguistically and cognitively. As well as "Engaging the children and encouraging them to express themselves interactively while building on their prior knowledge in real-life situations is an effective way to build language experience" (Cuevas, 1996; McLaughlin, 1984).

\subsection{Monolingual Families}

As we know that different cultures expose their infants to language in various ways, nonetheless, the outcome is almost the same as in acquiring the first language. Fluency in their first language happens to almost all children around the world. 
In other words, in an average family, child's language acquisition may not be considered a success, but rather part of child's biological development as it is not considered to be something extra than normal biological development. The most important thing is parents' interactive relation that results into contribution of child's cognitive development. The question is do children in monolingual families acquire the language faster than the ones in bilingual families;

"Virtually every child develops linguistic and communicative competence, and it is learned naturally and in context, not arranged in an easy-to-difficult sequence." Suggesting that language acquisition for infants is not a systematic process as it happens to adults when they decide to learn a new language; "The fact that both children and adults constantly communicate with a high degree of success is evidence that we are all following the same rules for appropriate communication behavior." (Lindfors, 1991; McLaughlin, 1984)

As to rephrase; our language development is a process of following the same rules that decide on the speed of acquisition which suggests that the number of languages being learned doesn't affect the speed of acquisition in an average family. Which brings up the idea of positive effects of teaching more than one language as it would help the child to cope with difficulties in a more enhanced way.

\subsection{Bilingual Families}

Most children in the world learn to speak two languages. Bilingualism is present in just about every country around the world, in all classes of society, and in all age groups. (Grosjean, 1982; McLaughlin, 1984)

Surprisingly, although children raised in bilingual environments have to learn roughly twice as much about language as their monolingual peers, the speed of acquisition is comparable in monolinguals and bilinguals.

Goodz (1994) suggests that bilingual children follow the same patterns as children considered to be monolingual and there is no real evidence for negative effect for bilinguals. Supporting the same viewpoint, Perez \& Torres (1996) mention that same patterns of communication skills problem solving thinking, acquiring information can be easily followed for another language in terms of proficiency development for bilingual children; "Children who develop proficiency in using their native language to communicate, to gain information, to solve problems, and to think can easily learn to use a second language in similar ways. (Pérez \& Torres-Guzmán, 1996, p. 96) Tabors (1997) points a significant element in discovering what language is; "Even young children who are learning a second language bring all of the knowledge about language learning they have acquired through developing their first language. For these children, then, second-language acquisition is not a process of discovering what language is, but rather of discovering what this language is. (Tabors, 1997, p. 12)

Language development before age five is quite crucial as all senses are open and children are ready to acquire all the information given in that regard, thus it's quite vital to make the best out of this period and to organize a setting together with parents' interactions with children in where children can obtain two or even more languages at the same time.

Although there have been negative approaches to bilingualism in terms of personality and identity development (Appel and Muysken, 1987), recent studies on bilingualism have brought biased evidence on the side of bilingualism claiming that it affects not only personality but also cognitive development of children; among them is McLaughlin, B. (Ed.). (2013), for example, arguing that it is not bilingualism but poor or weak societal settings that causes problems in children's personality development. The advantages of bilingualism have been excavated by many newly conducted studies claiming not only on personality but also on cognitive, intelligence, educational development etc. (Bialystok, 2001; Bialystok, Craik, Klein, and Viswanathan, 2004; Bialystok, Craik and Ryan, 2006; Martin-rhee \& Bialystok, 2008; Bialystok; 2011). 


\section{EDUCATIONAL PROBLEMS AND PERSONALITY DEVELOPMENT}

We as parents or teachers try to emphasize the importance of effort regardless its result while teaching children, even if they make mistakes or come up with unacceptable results. On the other hand, real life does vice versa as rewards are given to those who achieve success accepted by social norms, thus unmerited flattery may avoid revealing of true talents of children. At this point it is important to develop a healthy relationship between adults (parent or teacher) and children. "All learning takes place in the context of relationships and is critically affected by the quality of those relationships" (Norman-Murch, 1996). Thus, one of the main problems has been lying under misjudging or not realizing the true capabilitiesitalents of our children. The problems in education are kind of endless, here are just some subheadings:

\section{$1.1 \quad$ Truancy}

Truancy, as a collaborative misleading of parent-child interaction causes a great deal of gap in children's development as students, with parents' permission in many cases, stay away from school for quite a long time throughout the year. Sometimes parents even take their children on vacation at school time without being charged in any way as the rules are not conveying such problems. The main problem behind truancy is that students don't spend enough time at school and eventually fall back in many topics. "Truancy is also a strong predictor of juvenile problems, including delinquent activity, social isolation, gang involvement, educational failure, substance abuse, delinquency, teen pregnancy, and school dropout" (as cited in Trujillo, L. A. 2006).

\section{$2.1 \quad$ Use of drugs}

As a worldwide problem use of drugs has been one of the major problems facing children and the schools as institutions. The crucial relationships as the main principle in helping child progress for young aged children mental health, language development, personality development in at risk families in terms of drug usage, has been topic of research for many years. Recently, the focus by many researchers is mostly given to intervention at early ages as to prevent misconducts significantly to those who are lacking in development both linguistically and mentally. (Kalmanson \& Seligman, 1992; Weston et al, 1997; Greenspan et al, 1998; Miller \& Hanft, 1998; McCollum et al, 2001; Wilcox \& Weber, 2001; Pilkington \& Malinowski, 2002; Gilkerson \& Taylor Ritzler, in press).

On the other hand, children are still able to reach drugs, alcohol and tobacco products more easily. These substances are available everywhere and sold in legal or illegal ways. Governmental controls don't seem to be enough. Children can start these addictions by having been affected from their close friends. The consumption of these substances messes not only their bodies but also their spiritual worlds. There is a positive correlation between the usage of addiction and committing crime. The much consumption of drugs and alcohol cause the more criminal incidents. A child who commits the first crime becomes more likely to commit the subsequent crimes.

\subsection{Internet}

Following statistics taken from internet live statistics are worth to mention;

"Around $40 \%$ of the world population has an internet connection today. In 1995, it was less than $1 \%$. The number of internet users has increased tenfold from 1999 to 2013. The first billion was reached in 200, the second billion in 2010, and the third billion in 2014." (2015, April 20). Internet is an effective tool to reach information if it is used in this way. When the children access the internet, they are under the exposure of every kind of information. The access of sexual oriented web sites, gambling web sites are very easy. To prevent it, secure internet packages or protective programs must be supplied besides giving reasonable explanations to the child. Also social network creates another challenge for the parents. In the case of Facebook usage, personal pictures and information can be misused easily and be abused illegally. Chatting sites cause them to find imaginary friends and to create an unreal world that changes the child's character in an undesired way.

As mentioned earlier if schools can provide effective role models for students, they can be fostered in more benign settings with more qualified personnel, in other words, teachers as being role models for students they can prevent such 
misconducts of internet and instead they can improve students' personalities, educational sides by having them attended extracurricular activities or courses for learning the internet for better usage and purposes.

\section{CONCLUSION}

Moral values are of the essential elements in education. Morality refers to doing the right thing (behavior) for the right reason. Why are we honest, for example? Is it only because of altruistic feelings or because we see the rewards (benefits) of being honest (including the benefit of getting a good feeling)? That makes it a benefit oriented morality. Are we honest because we fear the consequences of being dishonest? That makes it a fear oriented morality.

If we are going to have a better society for today and the future, it is absolutely necessary to teach our kids moral values in school. One of the best ways to do this is to expose our children at the earliest age in school to positive role models in our society. Such a channel is first to test the qualities and side effects of role models, and then propose approaches that can find the intersection points for both teachers and students as to provide role models for students. As such positive role models are rarely found in families and societies, it is much more necessary for schools to involve moral values within their curriculums and provide representatives of role models as to complete the missing link between students and societies of their model citizens. Furthermore, "the public holds schools and teacher more accountable for student learning, as demonstrated by everyone's expectations for stronger student performances on standardized tests and higher graduation rates" (Lumpkin, A. 2008). In today's world when everything is valued with material measurements, we need people who can be models of the moral values, in other words, representatives of commitment, devotion, sacrifice etc. teachers with good qualities who are willing to drop tears for others' smiles. They should have these values, patience, enthusiasm, knowledge of the subject, good listeners, kind, fair, ability of stimulating students and such.

The practice of education starts within the family, thus, this article is mostly based on a more particular issue of parent child interaction in terms of gaining language development as it's the first step of child's personality development. Infancy and early childhood is the ideal time to let in your child in a foreign language. Babies gain understanding much before they can speak and benefit from having a rich language setting. It is because babies learn to talk by listening. This article together with recent studies suggest that the more words babies hear, the faster they learn to talk. The more often babies are exposed to daily language practices as well as social engagement in active interactions, the better cognitive skills are perceived in regard with language acquisition. One of the surprising facts suggested in our research is that bilingual learners are flexible and may acquire two languages in the time in which monolinguals acquire one.

\section{REFERENCES}

[1] Appel, R., \& Muysken, P. (1987). Bilingualism and language contact. London: Edward Arnold, 18.

[2] Bialystok, E., Craik, F. I., Klein, R., \& Viswanathan, M. (2004). Bilingualism, aging, and cognitive control: evidence from the Simon task. Psychology and aging, 19(2), 290.

[3] Bialystok, E., Craik, F. I., \& Ryan, J. (2006). Executive control in a modified antisaccade task: Effects of aging and bilingualism. Journal of Experimental Psychology: Learning, Memory, and Cognition, 32(6), 1341.

[4] Bialystok, Ellen. "Reshaping the mind: the benefits of bilingualism." Canadian Journal of Experimental Psychology/Revue canadienne de psychologie expérimentale 65.4 (2011): 229.

[5] Clark, Beverly A. "First-and Second-Language Acquisition in Early Childhood." (2000).

[6] Craik, F., \& Bialystok, E. (2005). Intelligence and executive control: Evidence from aging and bilingualism. Cortex, 41(2), 222-224.

[7] Gilkerson, L. \& Taylor Ritzler, T. (in press). The role of reflective process in infusing. Relationship-based practice into an early intervention system. In Finello, K.M. (Editor). The handbook of training and practice in infant and preschool mental health (January 2005). Jossey-Bass. 
[8] Goodz, N. S. (1994). Interactions between parents and children in bilingual families. In F. Genesee (Ed.), Educating second language children: The whole child, the whole curriculum, the whole community. Cambridge, England: Cambridge University Press. (ERIC Document No. ED375641)

[9] Greenspan, S., Weider, S., \& Simons, R. (1998). The child with special needs: Encouraging intellectual and emotional growth. Reading, Massachusetts: Perseus Books.

[10] Grosjean, F. (1982). Life with two languages. Cambridge, MA: Harvard University Press.

[11] Internetlivestats, (2015). Retrieved from: http://www.internetlivestats.com/internet-users/.

[12] Kalmanson, B., \& Seligman, S. (1992). Family-provider relationships: The basis of all interventions. Inf Young Children, 4(4): 46-52.

[13] Lindfors, J. W. (1991). Children's language and learning (2nd Ed.). Boston: Allyn and Bacon.

[14] Lumpkin, A. (2008). Teachers as role models teaching character and moral virtues. Journal of Physical Education, Recreation \& Dance, 79(2), 45-50.

[15] Martin-Rhee, M. M., \& Bialystok, E. (2008). The development of two types of inhibitory control in monolingual and bilingual children. Bilingualism: language and cognition, 11(01), 81-93.

[16] McCollum, J.A., Gooler, F.G., Appl, D.J., \& Yates, T.J. (2001). PIWl: enhancing parent-child interaction as a foundation for early intervention. Inf Young Children, 14 (1): 34-45.

[17] McLaughlin, B. (1984). Second language acquisition in childhood: Vol. 1. Preschool children (2nd ed.). Hillsdale, NJ: Erlbaum. (ERIC Document No. ED154604)

[18] McLaughlin, B. (Ed.). (2013). Second language acquisition in childhood: Volume 2: School-age Children. Psychology Press.

[19] Miller, J.L. \& Hanft, B.E. (1998). Building positive alliances: Partnerships with families as the cornerstone of developmental assessment. Inf Young Children, 11 (1): 49-60.

[20] National Scientific Council on the Developing Child. (2004). Young children develop in an environment of relationships. Waltham, Mass; Heller School for Social Policy and Management at Brandeis University.

[21] Norman-Murch, (1996). Reflective supervision as a vehicle for individual and organizational development. ZERO TO THREE, October/November 1996.

[22] Pérez, B., \& Torres-Guzmán, M. (1996). Learning in two worlds (2nd ed.). New York: Longman.

[23] Pilkington, K. and Malinowski, M (2002). The natural environment II: Uncovering deeper responsibilities within relationship-based services. Inf Young Children 2002; 15(2): 78-84.

[24] Rogoff, B. (1990). Apprenticeship in thinking: Cognitive development in social context. Oxford University Press.

[25] Tabors, P. (1997). One child, two languages. Baltimore, MD: Paul H. Brookes. (ERIC Document No. ED405987).

[26] Trujillo, L. A. (2006). School truancy: A case study of a successful truancy reduction model in the public schools. UC Davis Journal of Juvenile Law and Policy, 10, 69-95.

[27] Vygotsky, L. S. (1986). Thought and language (rev. ed.).

[28] Weston, D. Ivins, B. Heffron, M. \& Sweet, N. (1997). Formulating the centrality of relationships in early intervention: An organizational perspective. Inf Young Children, (9)3, 1-12. 
[29] Wilcox, M.J. \& Weber, C.A. (2001). Relationship-based practice in early intervention. Washington, D.C.; Poster presentation at the NAEYC National Institute for Early Childhood Professional Development. 